\title{
Factors Associated with Migration in Individuals Affected by Leprosy, Maranhão, Brazil: An Exploratory Cross-Sectional Study
}

\author{
C. Murto, ${ }^{1}$ C. Kaplan, ${ }^{2}$ L. Ariza, ${ }^{3}$ K. Schwarz, ${ }^{4}$ C. H. Alencar, ${ }^{3}$ \\ L. M. M. da Costa, ${ }^{5}$ and J. Heukelbach ${ }^{3,6}$ \\ ${ }^{1}$ Swiss Tropical and Public Health Institute, University of Basel, 4002 Basel, Switzerland \\ ${ }^{2}$ Hamovitch Center for Science in the Human Services, School of Social Work, University of Southern California, 1150 S. Olive Street, \\ Los Angeles, CA 90015, USA \\ ${ }^{3}$ Department of Community Health, School of Medicine, Federal University of Ceará, 60430-140 Fortaleza, CE, Brazil \\ ${ }^{4}$ School of Medicine, University of Cologne, Cologne, Germany \\ ${ }^{5}$ Leprosy Control Program, State Health Secretariat of Maranhão, 65076 Sao Luis, MA, Brazil \\ ${ }^{6}$ Anton Breinl Centre for Public Health and Tropical Medicine, School of Public Health, Tropical Medicine and Rehabilitation Sciences, \\ James Cook University, Townsville, QLD 4811, Australia
}

Correspondence should be addressed to J. Heukelbach; heukelbach@web.de

Received 9 May 2013; Accepted 9 August 2013

Academic Editor: Aditya Prasad Dash

Copyright (C) 2013 C. Murto et al. This is an open access article distributed under the Creative Commons Attribution License, which permits unrestricted use, distribution, and reproduction in any medium, provided the original work is properly cited.

\begin{abstract}
In Brazil, leprosy is endemic and concentrated in high-risk clusters. Internal migration is common in the country and may influence leprosy transmission and hamper control efforts. We performed a cross-sectional study with two separate analyses evaluating factors associated with migration in Brazil's Northeast: one among individuals newly diagnosed with leprosy and the other among a clinically unapparent population with no symptoms of leprosy for comparison. We included 394 individuals newly diagnosed with leprosy and 391 from the clinically unapparent population. Of those with leprosy, 258 (65.5\%) were birth migrants, 105 $(26.6 \%)$ were past five-year migrants, and $43(10.9 \%)$ were circular migrants. In multivariate logistic regression, three independent factors were found to be significantly associated with migration among those with leprosy: (1) alcohol consumption, (2) separation from family/friends, and (3) difficulty reaching the healthcare facility. Separation from family/friends was also associated with migration in the clinically unapparent population. The health sector may consider adapting services to meet the needs of migrating populations. Future research is needed to explore risks associated with leprosy susceptibility from life stressors, such as separation from family and friends, access to healthcare facilities, and alcohol consumption to establish causal relationships.
\end{abstract}

\section{Introduction}

Migration has been identified as one of the social determinants influencing transmission dynamics of Neglected Tropical Diseases (NTDs) [1, 2]. In fact, population movement can introduce new diseases when infected migrants move from endemic to nonendemic areas $[2,3]$. As strategies of disease control become increasingly important to meet World Health Organization (WHO) standards, a more thorough approach is needed to investigate migration as a risk factor for disease and determine factors associated with migration in a local context.
Migration can influence transmission of NTDs when circumstances influence conditions and risks associated with disease transmission, particularly among the poor who are disproportionately affected [4]. Environmental aspects as a consequence of poverty, such as poor sanitation and overcrowded substandard housing in areas of uncontrolled urbanization [3,5], as well as lifestyle stressors $[6,7]$ and behaviors associated with migration $[8,9]$ can increase susceptibility to infection and disease risk. Many of these factors have also been associated with leprosy transmission $[10,11]$.

It is estimated that 740 million people are internal migrants, a common condition of life in many low- and 
middle-income countries [12]. The reasons for migration are numerous and include drivers such as political conflict [13], disaster, and environmental change [14, 15], as well as socioeconomic determinants $[13,16]$. While migration is often a strategy to mitigate poverty [17], it is also a means to acquire capital for land, housing, and other opportunities $[18,19]$. Movement can be a strategy to realize a higher standard of living, access to better employment, education, and health service infrastructure, primarily between resource poor rural areas and urban centers $[5,13,17]$. These factors can influence short-term temporary or circular migration [17], or permanent relocation [16].

In Brazil, migration has historically taken place between poor rural areas in the northeast to large urban centers [20]. Strong social networks between these areas have facilitated ease and cost of movement, important factors in the decision to migrate [12]. A rural exodus of approximately 50 million people occurred between the 1950s and the 1980s, largely from the leprosy endemic Northeastern region. Until the 1970s, rural-urban migration was the result of urban industrialization. Secondarily, rural-rural migration was due to the modernization of agriculture and national policies for frontier expansion in the Amazon region. In the 1980s, severe drought in the Northeast affecting rural agriculture, coupled with severe economic decline throughout the country, influenced outmigration from the region. These decades saw the rapid expansion of urban slums and the expansion of settlements in the Amazon through migration, which has been hypothesized as a possible association with the increased distribution of leprosy in these areas $[10,21]$. In urban Rio de Janeiro, a primary destination site for migrants from the Northeast region, leprosy new case detection doubled in the 1980s [22].

The 1990s observed more localized regional migration [23]. While the majority of movement remains between urban centers [20], more recently, there has been a shift toward rural inmigration [20], which can be the result of return or circular migration to these areas.

As the Brazilian Ministry of Health ( $\mathrm{MoH})$ directs its efforts toward leprosy control in areas of high endemic leprosy transmission, interventions targeting high risk and vulnerable groups are an important strategy. Additional protocols should be developed which monitor the effect of population mobility on disease incidence $[2,3]$ and structure services to meet the needs and behavior of migrants. This development would be important as health systems often are not structured to accommodate migrating populations $[2,17]$.

The goal of the study reported in this paper was to support the Brazilian $\mathrm{MoH}$, Leprosy Control program in identifying unique factors associated with migration among those with leprosy in an effort to better target services to migrating populations. The study was designed as an exploratory study to investigate factors associated with migration among those newly diagnosed with leprosy in four endemic areas in the Northeast of Brazil, and separately, factors associated with migration among a clinically unapparent population for comparison. More than one-third of the collective population in the research sites in this study were inmigrants, born in areas outside of the municipality and $7 \%$ from outside of state of

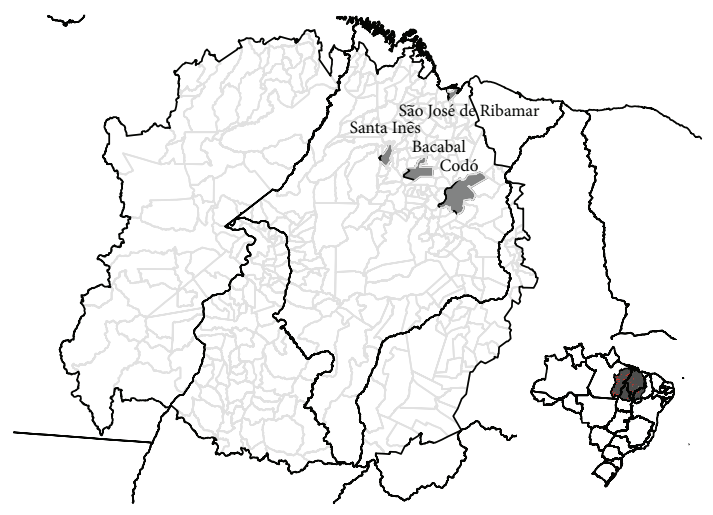

FIgURE 1: Map of Maranhão and four study sites (Santa Inês, São José de Ribamar, Codó, and Bacabal).

Maranhão [24]. The objectives were to identify demographic, socioeconomic, clinical, and psychosocial factors uniquely associated with migration among those with leprosy, as migration has been identified as a social determinant of health outcomes.

\section{Materials and Methods}

2.1. Study Area. Maranhão state has the third highest annual leprosy case detection rate in Brazil (5.34/10,000 inhabitants in 2010) [25]. The state ranks sixth on the list of outmigration among states and had a circular migration rate of $16.4 \%$ between 2004 and 2009 [26]. For this study, four highly endemic municipalities in Maranhão were selected: Santa Inês, São José de Ribamar, Codó, and Bacabal (Figure 1).

Each of these municipalities is located in a major endemic cluster identified by the Brazilian Ministry of Health as highrisk areas for leprosy transmission. Highly endemic clusters were based on national data from 2007 that identified a mean case detection rate of 7.6 per 10,000 residents among $11 \%$ of the population [27], well above the WHO elimination goal of $<1$ per 10,000 .

In 2009-2010, Bacabal had an average population size of 99,251 with a leprosy new case incidence of 12.85 per 10,000 inhabitants; Codó, 115,988 inhabitants with new case incidence of 9.40 per 10,000; São José de Ribamar, 151,260 inhabitants and new case incidence of 6.21 per 10,000; and Santa Inês, 81,490 inhabitants and new case incidence of 10.92 per 10,000 [24]. Nearly half of the populations of São José de Ribamar (44.3\%) and Santa Inês (45.6\%), 29.8\% in Bacabal and 17.9\% in Codó, were born in other municipalities in Maranhão. Those born outside of the state accounted for $11.2 \%$ of the population in Santa Inês, $9 \%$ of the population in Bacabal, $8.9 \%$ of the population in Codó, and $4.9 \%$ in São José de Ribamar [24].

2.2. Study Design. This exploratory population-based crosssectional study was designed to identify factors uniquely associated with migration among those with leprosy compared to nonmigrant residents and included a separate 


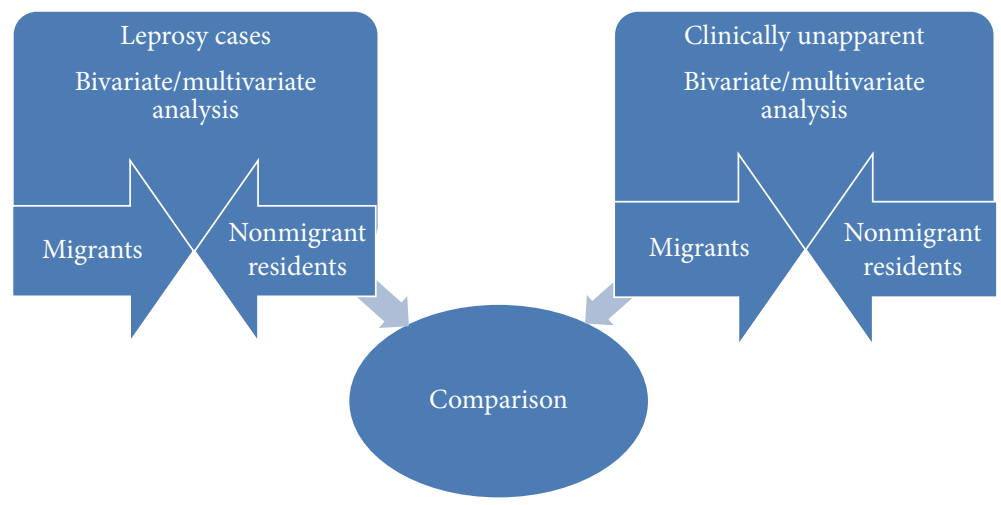

FIgURE 2: Study design.

analysis among individuals in a clinically unapparent population without symptoms of leprosy compared to nonmigrant residents. A comparison of factors associated with migration among those with leprosy to the clinically unapparent population was explored. Three dependent measures for migration were defined for both those with leprosy and separately for the clinically unapparent population: (1) migration after birth (municipality of birth different from current municipality of residence), (2) past five-year migration (migrated from a municipality different from the current residence in the last five-years), and (3) past five-year circular migration (past five-year migrants who were currently living in municipality of birth, but migrated to another municipality in the last five-years for a month or more). Migration included all population movement between municipalities, including ruralrural, rural-urban, and urban-urban movement. Figure 2 highlights the study design which includes bivariate and multivariate analyses conducted separately for birth, past five-year and circular migrants with leprosy compared to nonmigrant residents and similarly for migrants in the clinically unapparent population compared to residents. A detailed analysis of the comparison between migrants with leprosy and clinically unapparent migrants that was collected as part of the larger epidemiological study was beyond the scope of factors associated with migration among those with leprosy and will be explored elsewhere.

2.3. Data Collection. Data collection was conducted between April and July 2010 as part of a comprehensive epidemiological study conducted by the MAPATOPI project, an interdisciplinary project to support and improve the Brazilian leprosy control program in a major endemic cluster in the states of Maranhão, Tocantins, Piauí, and Pará, located in the North and Northeast regions of Brazil.

The leprosy population was identified through the database of the National Information System for Notifiable Diseases (Sistema de Informação de Agravos de Notificação (SINAN)) available from the Brazilian Ministry of Health, and included new leprosy cases diagnosed in 2009-2010, aged $>15$ years, and living in the four highly endemic municipalities. A clinically unapparent population without symptoms of leprosy, matched to leprosy cases by age, sex and geographic location, was selected from the Programa Saúde da Família (Program for Family Health) and evaluated for leprosy through an extensive clinical exam. Both leprosy cases and those in the clinically unapparent population with a prior history of leprosy or leprosy relapse, living outside of the endemic municipalities and those who could not be located through multiple contact attempts, were excluded.

2.4. Field Procedures and Survey Instrument. The Municipality Health Secretariats were informed by the Maranhão State Health Secretariat about the study, and field visits were coordinated for data collection. Patients were invited through community health agents to participate and to be interviewed at the local health care centers. Home visits, often accompanied by local community health agents, were performed when individuals did not present at the health care center or had difficulty attending due to age or disability.

A structured questionnaire was used and composed of seven sections: (1) sociodemographics (sex, age, marital status, education, and employment), (2) housing/economic variables (household density, household income, area of residence, and utility access), (3) clinical/disease-related (clinical form of the disease, operational classification, and grade of disability at diagnosis), (4) health services (visits by community health worker, access to health services), (5) migration (history of migration and length of time at residence), (6) behavior (experienced hunger, alcohol consumption, type, and frequency), and (7) stress (from disease, job/salary loss, divorce/separation, separation from family/friends, and death of close family/friend). Clinical data was also collected from patients' charts. As data from patients' charts was provided through the local healthcare center, in some cases complete data was unavailable.

2.5. Data Analysis. Data were entered twice, using Epi Info software version 3.5.1 (Centers for Disease Control and Prevention, Atlanta, USA), and crosschecked for entryrelated errors. Statistical tests were used to assess normality. Data analysis was conducted using STATA version 11 (Stata Corporation, College Station, USA). As a first step, a series of bivariate analyses were conducted examining the significant differences in key theoretical variables for: (i) migrants with 
leprosy after birth compared to nonmigrant residents with leprosy, (ii) migrants after birth in a clinically unapparent population compared to nonmigrant residents in a clinically unapparent population, (iii) past 5-year migrants with leprosy compared to nonmigrant residents with leprosy, (iv) past 5-year migrants in a clinically unapparent population compared to nonmigrant residents in a clinically unapparent population, (v) past 5-year circular migrants with leprosy compared to nonmigrant residents with leprosy, and (vi) past 5 -year circular migrants in a clinically unapparent population compared to nonmigrant residents in a clinically unapparent population. Significant differences $(P<0.05)$ in the hypothesized variables in these analyses were determined with Fisher's exact tests. Odds ratios and 95\% confidence intervals were also computed. In the second step, a series of multivariate analyses were executed. The hypothesized variables found to be significant for each migrant group were included in separate multiple logistic regression models for each migrant group controlling for age, sex, and geographic location. A backwards stepwise approach was used to construct these models.

2.6. Ethics. The study was approved by the Ethical Review Board of the Federal University of Ceará (Fortaleza, Brazil). Permission to perform the study was also obtained by the Maranhão State Health Secretariat, the State Leprosy Control Program, and municipalities involved. Informed written consent was obtained from study participants after explaining the objectives of the study, and interviews were conducted in private.

\section{Results}

3.1. Study Population Characteristics. This study included 394 individuals newly diagnosed with leprosy and 391 individuals from a clinically unapparent population. A total of 135 individuals were not interviewed because they were either not located at their documented place of residence $(n=$ 41 ), had moved ( $n=34)$, or had been transferred to a healthcare facility in another municipality after diagnosis $(n=18)$. Another 18 were traveling/away/working, 2 were incarcerated, and 6 were excluded due to mental disability. Others were ill or hospitalized $(n=3)$, or the place of residence was not reachable/outside of municipality $(n=4)$. Only 8 individuals refused to participate.

Of the 394 individuals with leprosy, 215 (54.6\%) were males and 179 (45.4\%) were females, ranging in age from 15 to 86 years $($ mean $=42.9$ years; standard deviation $=18.8)$. In the clinically unapparent population $(n=391), 216(55.2 \%)$ were males and 175 (44.8\%) were females, aged 15 to 89 years $($ mean $=42.6$; standard deviation $=18.8)$. More than onethird of the individuals with leprosy were working $(n=140$; $35.5 \%)$, and 254 (64.5\%) were unemployed, while 159 (40.7\%) in the clinically unapparent population were working and 232 (59.3\%) unemployed. Nearly half $(n=218,44.7 \%)$ of those with leprosy were illiterate, as compared to 137 (35.0\%) from the clinically unapparent population. The mean monthly household income was $\mathrm{R} \$ 924$ among those with leprosy and
$\mathrm{R} \$ 906$ in the clinically unapparent population. More than one in four among those with leprosy $(n=169,44.4 \%)$ and 159 (42.9\%) in the clinically unapparent population were living on less than one minimum wage per month $(\mathrm{R} \$ 551 \approx \mathrm{USD}$ \$296).

Leprosy-affected individuals included 228 (63.8\%) who were classified with multibacillary leprosy. The majority did not have disability at diagnosis (Grade 0$)(n=146,58.2 \%)$, which was followed by Grade I $(n=82,32.7 \%)$ and Grade II $(n=23,9.2 \%)$ disabilities. The clinical form of leprosy was primarily borderline $(n=166,46.9 \%)$, followed by tuberculoid ( $n=82,23.2 \%)$, lepromatous ( $n=47,13.3 \%)$, indeterminate $(n=44,12.4 \%)$, and neural leprosy $(n=15,4.2 \%)$.

Of those with leprosy, 258 (65.5\%) were birth migrants, $105(26.6 \%)$ were migrants in the past five-years, and 43 (10.9\%) were circular migrants. The clinically unapparent population included $266(68.0 \%)$ birth migrants, 81 (20.7\%) past five-year migrants, and $32(8.2 \%)$ circular migrants.

Variables from the bivariate analysis associated with migration $(P<0.05)$ were included in the multivariate models.

3.2. Factors Associated with Migration after Birth. Among birth migrants with leprosy, demographic, behavioral, and clinical factors were found to be associated with migration (Table 1) compared to nonmigrant residents with leprosy (not shown). Behavioral variables included life stressors and alcohol consumption among those with leprosy. Stress as a result of separation from family and friends was associated with migration as was drinking alcohol currently. Not being formally employed by being either employed monthly, daily, or self-employed was significantly associated with migration among those with leprosy as was borderline leprosy diagnosis. Stress from separation from family and friends, never worked, and migration among those 45 and older were found to be associated with migrants in the clinically unapparent population (Table 2) compared to clinically unapparent nonmigrant residents (not shown).

3.3. Factors Associated with Migration in the Past Five-Years. Similar to birth migrants, behavioral and lifestyle stressor variables were also associated with migration among those with leprosy (Table 3) compared to nonmigrant residents with leprosy (not shown). Separation from family and friends was significantly associated with migration, as was current alcohol consumption. Two other key factors emerged that differentiated past five-year migrants with leprosy from both birth migrants and migrants in the clinically unapparent population: short length of residence in the current household and difficulty in reaching the healthcare center. Among those in the clinically unapparent population (Table 4), separation from family and friends remained significantly associated with migration when compared to clinically unapparent nonmigrant residents (not shown). Ages 45 and older were no longer associated with past five-year migration in this group. Rather, ages 30 and older were found to be a deterrent to recent migration. Income less than minimum wage $(\mathrm{R} \$ 511)$ 
TABLE 1: Multivariate analysis of factors associated with migration after birth among migrants diagnosed with leprosy compared to nonmigrant residents with leprosy.

\begin{tabular}{|c|c|c|c|}
\hline \multicolumn{4}{|c|}{ Migration after birth } \\
\hline \multicolumn{4}{|c|}{ Leprosy cases } \\
\hline & $\begin{array}{c}\text { Migrants }^{\dagger} \\
N=258 \\
(66.2 \%)\end{array}$ & $\operatorname{AOR}(95 \% \mathrm{CI})^{*}$ & $P$ \\
\hline \multicolumn{4}{|l|}{$\begin{array}{l}\text { Worker contract status } \\
\text { (employed) }\end{array}$} \\
\hline Formally employed & $18(45.0 \%)$ & 1.0 & \\
\hline Self-employed & $13(68.4 \%)$ & $\begin{array}{c}15.27 \\
(1.44-161.69)\end{array}$ & 0.02 \\
\hline Monthly employment & $14(73.7 \%)$ & $8.83(1.53-50.81)$ & 0.02 \\
\hline Day labour & $43(74.1 \%)$ & $10.35(2.59-41.31)$ & 0.001 \\
\hline \multicolumn{4}{|l|}{ Alcohol consumption } \\
\hline Never drank & $54(53.5 \%)$ & 1.0 & \\
\hline Drink currently & $38(67.9 \%)$ & $14.53(1.64-128.31)$ & 0.02 \\
\hline Drank in past $5 \mathrm{yrs}$ & $120(68.6 \%)$ & $5.65(0.95-33.45)$ & 0.56 \\
\hline $\begin{array}{l}\text { Stopped drinking }>5 \\
\text { years ago }\end{array}$ & $41(80.4 \%)$ & $6.69(0.65-69.15)$ & 0.11 \\
\hline \multicolumn{4}{|l|}{$\begin{array}{l}\text { Difficulty to reach the } \\
\text { healthcare center }\end{array}$} \\
\hline Yes & $73(76.8 \%)$ & $0.91(0.20-4.17)$ & 0.91 \\
\hline No & $184(62.8 \%)$ & 1.0 & \\
\hline \multicolumn{4}{|l|}{$\begin{array}{l}\text { Stress separated from } \\
\text { family/friends }\end{array}$} \\
\hline Yes & $57(78.1 \%)$ & $7.64(1.25-46.71)$ & 0.03 \\
\hline No & $200(63.3 \%)$ & 1.0 & \\
\hline \multicolumn{4}{|l|}{ Stress job/salary loss } \\
\hline Yes & $77(77.0 \%)$ & $0.92(0.25-3.48)$ & 0.91 \\
\hline No & $180(62.3 \%)$ & 1.0 & \\
\hline \multicolumn{4}{|l|}{ Leprosy diagnosis } \\
\hline Tuberculoid & $48(59.3 \%)$ & $4.36(0.79-24.11)$ & 0.09 \\
\hline Borderline & $123(75.5 \%)$ & $5.41(1.01-29.14)$ & 0.049 \\
\hline Lepromatous & $27(57.5 \%)$ & $0.15(0.02-1.33)$ & 0.09 \\
\hline Indeterminate & $22(50.0 \%)$ & 1.0 & \\
\hline Neural & $9(60.0 \%)$ & $0.84(0.03-21.87)$ & 0.92 \\
\hline
\end{tabular}

${ }^{\dagger}$ Data not available for all individuals, significant results at $95 \%(P<0.05)$ are highlighted in bold, ${ }^{*}$ adjusted odds rates (AOR) are only presented for those variables included in the final regression model.

was also associated with migration in the clinically unapparent population, although no public waste collection, which is sometimes used as a proxy for poverty, was protective.

3.4. Factors Associated with Circular Migration Five-Years before Diagnosis. Stressors and behavior were associated with circular migration among those with leprosy (Table 5) compared to nonmigrant residents with leprosy (not shown), consistent with findings among both past five-year and birth migrants. Stress from separation from family and friends was associated with migration among both circular migrants with
TABLE 2: Multivariate analysis of factors associated with migration after birth among migrants in a clinically unapparent population without symptoms of leprosy compared to clinically unapparent non-migrant residents.

\begin{tabular}{|c|c|c|c|}
\hline \multicolumn{4}{|c|}{ Migration after birth } \\
\hline \multicolumn{4}{|c|}{ Clinically unapparent population } \\
\hline & $\begin{array}{c}\text { Migrants }^{\dagger} \\
N=266(68.4 \%)\end{array}$ & $\operatorname{AOR}(95 \% \mathrm{CI})^{*}$ & $P$ \\
\hline \multicolumn{4}{|l|}{ Age-groups (yrs) } \\
\hline $15-29$ & $71(55.0 \%)$ & 1.0 & \\
\hline $30-44$ & $54(64.3 \%)$ & $1.20(0.65-2.2)$ & 0.56 \\
\hline $45-59$ & $67(77.9 \%)$ & $2.4(1.15-5.01)$ & 0.02 \\
\hline$\geq 60$ & $74(82.2 \%)$ & $3.08(1.3-7.31)$ & 0.01 \\
\hline \multicolumn{4}{|l|}{ Sex } \\
\hline Male & $157(72.7 \%)$ & $1.27(0.79-2.03)$ & 0.32 \\
\hline Female & $109(63.0 \%)$ & 1.0 & \\
\hline \multicolumn{4}{|l|}{ Education } \\
\hline No formal education & $107(78.7 \%)$ & $1.20(0.62-2.34)$ & 0.59 \\
\hline Some education & $159(62.9 \%)$ & 1.0 & \\
\hline \multicolumn{4}{|l|}{ Life occupation } \\
\hline Farmer & $105(76.6 \%)$ & $0.80(0.43-1.49)$ & 0.48 \\
\hline Never worked & $20(40.0 \%)$ & $0.39(0.2-0.78)$ & 0.01 \\
\hline Other work & $139(69.5 \%)$ & 1.0 & \\
\hline $\begin{array}{l}\text { Stress separated from } \\
\text { family/friends }\end{array}$ & $55(78.6 \%)$ & $2.35(1.22-4.51)$ & \\
\hline Yes & $55(78.6 \%)$ & $2.35(1.22-4.51)$ & 0.01 \\
\hline No & $211(66.1 \%)$ & 1.0 & \\
\hline
\end{tabular}

${ }^{\dagger}$ Data not available for all individuals, significant results at $95 \%(P<0.05)$ are highlighted in bold, ${ }^{*}$ adjusted odds rates (AOR) are only presented for those variables included in the final regression model.

leprosy compared to nonmigrant residents with leprosy, as well as clinically unapparent migrants (Table 6) compared to clinically unapparent nonmigrant residents (not shown). Unique to migrants with leprosy, current alcohol consumption as well as difficulty in reaching the healthcare center was associated with circular migration. Age 45-59 was a significant deterrent to migration among those with leprosy, while age 60 and older was only marginally protective.

\section{Discussion}

The role of social inequalities is in the forefront of Neglected Tropical Diseases (NTDs), underscoring the deep divide that places the most marginalized at highest risk for infection $[10,15]$. Among environmental, socioeconomic, and cultural risks, migration is suggested to be a determinant for NTDs [28]. Migration interacts with these factors when fundamental social inequalities determine the necessity to migrate and conditions of migration. This can place migrants at heightened risk for disease while extending disease distribution into new areas.

In this study we assessed factors associated with migration among those with leprosy in Northeast Brazil. We 
TABLE 3: Multivariate analysis of factors associated with past 5 year migration among migrants diagnosed with leprosy compared to non-migrant residents with leprosy.

\begin{tabular}{|c|c|c|c|}
\hline & $\begin{array}{c}\text { st } 5 \text {-year migrati } \\
\text { Leprosy cases } \\
\text { Migrants }^{\dagger} \\
N=105(26.7)\end{array}$ & $\operatorname{AOR}(95 \% \mathrm{CI})^{*}$ & $P$ \\
\hline \multicolumn{4}{|l|}{ Age-groups (yrs) } \\
\hline $15-29$ & $43(33.6 \%)$ & 1.0 & \\
\hline $30-44$ & $29(33.7 \%)$ & $0.75(0.35-1.58)$ & 0.45 \\
\hline $45-59$ & $19(21.8 \%)$ & $0.57(0.24-1.3)$ & 0.28 \\
\hline$\geq 60$ & $14(15.2 \%)$ & $0.45(0.16-1.31)$ & 0.14 \\
\hline \multicolumn{4}{|l|}{ Education } \\
\hline No formal education & $34(19.4 \%)$ & $0.66(0.29-1.49)$ & 0.32 \\
\hline Some education & $71(32.6 \%)$ & 1.0 & \\
\hline \multicolumn{4}{|l|}{$\begin{array}{l}\text { Head of household } \\
\text { education }\end{array}$} \\
\hline No formal education & $42(20.4 \%)$ & $0.90(0.43-1.85)$ & 0.77 \\
\hline Some education & $54(32.5 \%)$ & 1.0 & \\
\hline \multicolumn{4}{|l|}{ Life occupation } \\
\hline Farmer & $31(21.2 \%)$ & $0.83(0.41-1.68)$ & 0.60 \\
\hline Never worked & $12(23.5 \%)$ & $0.77(0.29-2.02)$ & 0.59 \\
\hline Other work & $62(31.0 \%)$ & 1.0 & \\
\hline \multicolumn{4}{|l|}{ Electricity } \\
\hline No & $4(80.0 \%)$ & $\begin{array}{c}14.75 \\
(1.09-199.83)\end{array}$ & 0.43 \\
\hline Yes & $101(26.0 \%)$ & 1.0 & \\
\hline \multicolumn{4}{|l|}{$\begin{array}{l}\text { Length of time in } \\
\text { current residence }\end{array}$} \\
\hline $0-4$ years & $61(43.0 \%)$ & $2.51(1.37-4.63)$ & 0.003 \\
\hline $5-10$ years & $12(17.4 \%)$ & $0.74(0.31-1.77)$ & 0.50 \\
\hline$\geq 11$ years & $30(17.7 \%)$ & 1.0 & \\
\hline \multicolumn{4}{|l|}{ Alcohol consumption } \\
\hline Never drank & $18(17.7 \%)$ & 1.0 & \\
\hline Drink currently & $19(33.9 \%)$ & $2.52(1.01-6.28)$ & 0.047 \\
\hline Drank in past 5 yrs & $56(31.8 \%)$ & $1.88(0.87-4.07)$ & 0.12 \\
\hline $\begin{array}{l}\text { Stopped drinking } \\
>5 \text { yrs ago }\end{array}$ & $10(19.6 \%)$ & $1.40(0.48-4.11)$ & 0.54 \\
\hline \multicolumn{4}{|l|}{$\begin{array}{l}\text { Difficulty to reach the } \\
\text { healthcare centre }\end{array}$} \\
\hline Yes & $36(37.9 \%)$ & $2.23(1.22-4.09)$ & 0.01 \\
\hline No & $69(23.3 \%)$ & 1.0 & \\
\hline \multicolumn{4}{|l|}{ Stress job/salary loss } \\
\hline Yes & $38(37.3 \%)$ & $1.54(0.81-2.94)$ & 0.19 \\
\hline No & $67(23.1 \%)$ & 1.0 & \\
\hline \multicolumn{4}{|l|}{ Stress divorce/separated } \\
\hline Yes & $26(37.7 \%)$ & $0.76(0.35-1.63)$ & 0.48 \\
\hline No & $79(24.5 \%)$ & 1.0 & \\
\hline \multicolumn{4}{|l|}{$\begin{array}{l}\text { Stress separated from } \\
\text { family/friends }\end{array}$} \\
\hline Yes & $34(46.0 \%)$ & $2.64(1.36-5.10)$ & 0.004 \\
\hline No & $71(22.3 \%)$ & 1.0 & \\
\hline
\end{tabular}

${ }^{\dagger}$ Data not available for all individuals, significant results at $95 \%(P<0.05)$ are highlighted in bold, ${ }^{*}$ adjusted odds rates (AOR) are only presented for those variables included in the final regression model.
TABLE 4: Multivariate analysis of factors associated with past 5 year migration among migrants in a clinically unapparent population without symptoms of leprosy compared to clinically unapparent non-migrant residents.

\begin{tabular}{|c|c|c|c|}
\hline \multicolumn{4}{|c|}{$\begin{array}{l}\text { Past 5-year migration } \\
\text { Clinically unapparent population }\end{array}$} \\
\hline & $\begin{array}{c}\text { Migrants }^{\dagger} \\
n=81(20.7)\end{array}$ & $\operatorname{AOR}(95 \% \mathrm{CI})^{*}$ & $P$ \\
\hline \multicolumn{4}{|l|}{ Age-groups (yrs) } \\
\hline $15-29$ & $41(31.3 \%)$ & 1.0 & \\
\hline $30-44$ & $22(26.2 \%)$ & $0.72(0.34-1.55)$ & 0.02 \\
\hline $45-59$ & $11(12.8 \%)$ & $0.3(0.11-0.84)$ & 0.02 \\
\hline$\geq 60$ & $7(7.8 \%)$ & $0.23(0.07-0.78)$ & 0.01 \\
\hline \multicolumn{4}{|l|}{ Education } \\
\hline No formal education & $15(11.0 \%)$ & $1.04(0.35-3.1)$ & 0.9 \\
\hline Some education & $66(26.0 \%)$ & 1.0 & \\
\hline \multicolumn{4}{|l|}{$\begin{array}{l}\text { Head of household } \\
\text { education }\end{array}$} \\
\hline No formal education & $22(12.5 \%)$ & $0.61(0.27-1.4)$ & 0.25 \\
\hline Some education & $53(26.2 \%)$ & 1.0 & \\
\hline \multicolumn{4}{|l|}{ Life occupation } \\
\hline Farmer & $18(13.1 \%)$ & $1.57(0.66-3.72)$ & 0.3 \\
\hline Never worked & $13(26.0 \%)$ & $0.94(0.38-2.32)$ & 0.89 \\
\hline Other work & $49(24.3 \%)$ & 1.0 & \\
\hline \multicolumn{4}{|l|}{ Home ownership } \\
\hline No & $10(55.6 \%)$ & $\begin{array}{c}3.34 \\
(0.99-11.25)\end{array}$ & 0.05 \\
\hline Yes & $71(19.1 \%)$ & 1.0 & \\
\hline \multicolumn{4}{|l|}{$\begin{array}{l}\text { Household monthly } \\
\text { income }{ }^{\dagger \dagger}\end{array}$} \\
\hline$>511 \mathrm{R} \$$ & $54(25.5 \%)$ & 1.0 & \\
\hline $0-511 \mathrm{R} \$$ & $26(16.4 \%)$ & $2.15(1.09-4.23)$ & 0.02 \\
\hline \multicolumn{4}{|l|}{ Public waste collection } \\
\hline No & $11(11.9 \%)$ & $0.43(0.19-0.97)$ & 0.03 \\
\hline Yes & $70(23.7 \%)$ & 1.0 & \\
\hline \multicolumn{4}{|l|}{$\begin{array}{l}\text { Stress separated from } \\
\text { family/friends }\end{array}$} \\
\hline Yes & $34(48.6 \%)$ & $5.76(2.96-11.22)$ & $<0.0001$ \\
\hline No & $47(14.6 \%)$ & 1.0 & \\
\hline${ }^{\dagger}$ Data not available for all in & ndividuals, ${ }^{\dagger \dagger}$ at th & e time of the survey & US\$ was \\
\hline
\end{tabular}

found several distinct behavioral and psychosocial factorslife stressors, alcohol consumption, and healthcare accessuniquely associated with migration among individuals with leprosy. Alcohol consumption and healthcare access were not associated with migration in a clinically unapparent population, while life stressors were associated with migrant lifestyle regardless of disease.

We examined socioeconomic status, key demographics, and household environment, as these features have been 
TABLE 5: Multivariate analysis of factors associated with past 5 year circular migration among migrants diagnosed with leprosy compared to non-migrant residents with leprosy.

\begin{tabular}{|c|c|c|c|}
\hline \multicolumn{4}{|c|}{ Past 5-year circular migration } \\
\hline \multicolumn{4}{|c|}{ Leprosy cases } \\
\hline & $\begin{array}{c}\text { Migrants }^{\dagger} \\
n=43(24.57)\end{array}$ & $\operatorname{AOR}(95 \% \mathrm{CI})^{*}$ & $P$ \\
\hline \multicolumn{4}{|l|}{ Age-groups (years) } \\
\hline $15-29$ & $25(32.1 \%)$ & 1.0 & \\
\hline $30-44$ & $13(31.7 \%)$ & $0.82(0.29-2.29)$ & 0.7 \\
\hline $45-59$ & $3(10.0 \%)$ & $0.17(0.04-0.79)$ & 0.02 \\
\hline$\geq 60$ & $2(7.7 \%)$ & $0.1(0.01-1.12)$ & 0.06 \\
\hline \multicolumn{4}{|l|}{ Education } \\
\hline No formal education & $10(15.9 \%)$ & $0.84(0.25-2.8)$ & 0.77 \\
\hline Some education & $33(29.5 \%)$ & 1.0 & \\
\hline \multicolumn{4}{|l|}{$\begin{array}{l}\text { Head of household } \\
\text { education }\end{array}$} \\
\hline No formal education & $15(17.1 \%)$ & $0.57(0.22-1.49)$ & 0.26 \\
\hline Some education & $25(32.5 \%)$ & 1.0 & \\
\hline \multicolumn{4}{|l|}{ Alcohol consumption } \\
\hline Never drank & $6(11.3 \%)$ & 1.0 & \\
\hline Drink currently & $12(40.0 \%)$ & $4.46(1.3-15.34)$ & 0.02 \\
\hline Drank in past 5 years & $22(28.6 \%)$ & $2.26(0.7-7.29)$ & 0.17 \\
\hline $\begin{array}{l}\text { Stopped drinking } \\
>5 \text { years ago }\end{array}$ & $2(16.7 \%)$ & $\begin{array}{c}2.47 \\
(0.27-22.92)\end{array}$ & 0.43 \\
\hline \multicolumn{4}{|l|}{$\begin{array}{l}\text { Difficulty to reach the } \\
\text { healthcare centre }\end{array}$} \\
\hline Yes & $16(42.1 \%)$ & $2.72(1.07-6.93)$ & 0.04 \\
\hline No & $27(19.9 \%)$ & 1.0 & \\
\hline \multicolumn{4}{|l|}{ Time to Diagnosis } \\
\hline$<7$ days & $25(25.3 \%)$ & 1.0 & \\
\hline 7-30 days & $11(29.0 \%)$ & $1.14(0.41-3.17)$ & 0.8 \\
\hline $30-60$ days & $1(20.0 \%)$ & $1.39(0.1-19.1)$ & 0.81 \\
\hline$>60$ days & $6(20.7 \%)$ & $1.18(0.33-4.2)$ & 0.8 \\
\hline \multicolumn{4}{|l|}{$\begin{array}{l}\text { Stress separated from } \\
\text { family/friends }\end{array}$} \\
\hline Yes & $14(46.7 \%)$ & $4.71(1.66-13.41)$ & 0.004 \\
\hline No & $29(20.0 \%)$ & 1.0 & \\
\hline
\end{tabular}

${ }^{\dagger}$ Data not available for all individuals, significant results at $95 \%(P<0.05)$ are highlighted in bold, ${ }^{*}$ adjusted odds rates (AOR) are only presented for those variables included in the final regression model.

associated with NTDs risk [2, 28] and migration [12, 17]. However, the majority of these social factors were not found to be associated with migration in Maranhão in this exploratory study. This suggests a high level of social homogeneity between nonmigrant residents and migrants residing in the interior and leprosy endemic areas of the state and also may indicate that social features which are prominent in migrating populations are less pronounced when looking at a vulnerable population, such as those affected by leprosy. Household and family exposure to leprosy, the primary exposure risk for leprosy infection, was also
TABLE 6: Multivariate analysis of factors associated with past 5 year circular migration among migrants in a clinically unapparent population without symptoms of leprosy compared to clinically unapparent non-migrant residents.

\begin{tabular}{|c|c|c|c|}
\hline \multicolumn{4}{|c|}{ Past 5 year circular migration } \\
\hline \multicolumn{4}{|c|}{ Clinically unapparent population } \\
\hline & $\begin{array}{c}\text { Migrants }^{\dagger} \\
n=32(20.65)\end{array}$ & $\operatorname{AOR}(95 \% \mathrm{CI})^{*}$ & $P$ \\
\hline \multicolumn{4}{|l|}{ Life occupation } \\
\hline Farmer & $7(18.0 \%)$ & $0.55(0.21-1.5)$ & 0.23 \\
\hline Never worked & $3(9.1 \%)$ & $0.27(0.08-1.03)$ & 0.06 \\
\hline Other work & $22(26.5 \%)$ & 1.0 & \\
\hline \multicolumn{4}{|c|}{$\begin{array}{l}\text { Stress separated from } \\
\text { family/friends }\end{array}$} \\
\hline Yes & $10(40.0 \%)$ & $3.36(1.3-8.66)$ & 0.01 \\
\hline No & $22(16.9 \%)$ & 1.0 & \\
\hline
\end{tabular}

${ }^{\dagger}$ Data not available for all individuals, significant results at $95 \%(P<0.05)$ are highlighted in bold, ${ }^{*}$ adjusted odds rates (AOR) are only presented for those variables included in the final regression model.

not found to be significant when comparing migrants with nonmigrant residents with leprosy. However, future research should consider the role of family and other leprosy contact exposure during migration.

Separation from family and friends, considered a prominent life stressor [29], was found to be significantly associated with migration. Stress can impact psychological well-being and trigger changes to the biological system of the human body and has also been found to be associated with compromised immune response and activation of latent infection for infectious disease [30, 31]. For migrants, stress may render one more vulnerable to infectious diseases such as leprosy and influence symptom onset for those previously exposed.

While stress from separation from family and friends was prominent among migrants regardless of leprosy infection, the odds of this stressor among birth and circular migrants were higher than those of migrants in the clinically unapparent population. Lack of social support that would be more readily available in the home environment can negatively influence the psychological adjustment process among those who migrate $[6,7]$ and has also been found to increase susceptibility to anxiety and depression among migrants [7]. The collective construction of family in Brazil through extended family and intergenerational participation [32] takes a significant role in Brazilian culture, and in our study, the majority of migrants lived with family members during the past five-year migration period. Poverty, however, has led to increased family separation and interregional migration in Brazil [33], most likely separation from the nuclear family due to cost of migration while maintaining extended familial social networks for employment. Irregular noncontractual employment, as was found among birth migrants, often necessitates separation from family when the cost of migration, particularly to urban areas, cannot accommodate nuclear family movement. Day labour was less 
likely among those aged 60 and older, and self and monthly employments were more likely among those aged 45-59.

Social stressors can also lead to other behavioral risk such as alcohol abuse [34], and in this study we found that current alcohol consumption differentiates migrants with leprosy from clinically unapparent population. Migration-associated alcohol consumption has been well documented $[8,9,35]$ and has also been found to be associated with mycobacterial disease [36] and increased susceptibility to infection [37], which may be relevant in terms of susceptibility to leprosy infection. In Maranhão, current alcohol consumption was found to be a significant factor for those newly diagnosed with leprosy who are birth, past five-year, and circular migrants compared to nonmigrant residents with leprosy. This is particularly concerning among those newly diagnosed with leprosy in terms of interaction with treatment protocols, as alcohol has been found to be a major predictor of leprosy relapse [38], which may stem from the effects of alcohol on the absorption of antibiotics [39]. In addition, liver function among those with more severe lepromatous leprosy is compromised and alcohol consumption should be considered in terms of risk for relapse, susceptibility and disease onset. Younger males in Maranhão were the most likely to drink alcohol which is consistent with other research among migrants [9].

Social isolation can accompany those who migrate, particularly in countries such as Brazil where the culture validates the role of family relationships in daily life. Alcohol used as a coping mechanism can be expressed as regular alcohol consumption [35], but also substance abuse [8] and binge drinking [9]. The odds of current alcohol use were fourteen times higher for birth migrants, twice as high for past five-year migrants, and four times higher for circular migrants with leprosy compared to nonmigrant residents with leprosy. Contrarily, alcohol consumption did not differentiate migrants from nonmigrant residents in the clinically unapparent population.

In Maranhão, past five-year and circular migrants with leprosy had a significantly higher chance of having difficulty reaching the healthcare center than nonmigrant residents with leprosy, while there was no significant difference among migrants and nonmigrant residents in the clinically unapparent population. In fact, healthcare infrastructure is often not compatible to the needs of migrating populations $[2,17]$. Long hours of employment and unfamiliarity with new living environments are elements that can affect migrant health access, even when symptoms are evident and persistent. Many municipalities in Brazil have adapted their service availability to some extent, with primary healthcare centers now providing hours that accommodate the working population.

Distance and illness were the primary reasons for having difficulty in accessing the health clinics among those with leprosy in our study, and other research has also found that migration was a barrier to health facility utilization [7]. Short length of residence among past five-year migrants may partially explain difficulty in reaching the healthcare center, as this could be an additional barrier to access for those who are unfamiliar with the region or lack local social support to locate local services. On a positive note, results are from those currently receiving treatment through their local health center, and another study found that migration is not a barrier to treatment interruption in Brazil after diagnosis [40]. It is nonetheless relevant to point out that illness and distance are significantly higher for migrants than for nonmigrant residents with leprosy, and failing to reach migrating populations may hinder control efforts [41].

The three main factors-lifestyle stress, alcohol consumption, and healthcare access-present important considerations in the role of risks associated with migration and consequently disease control. In their advanced expression, alcohol abuse and significant psychological distress not only affect immune system response but can also contribute to delay in accessing health services, late diagnosis, and treatment interruption $[7,42]$. Thus, it continues to be important to identify mechanisms and adaptations for leprosy control efforts to respond to unique risks associated with migration.

There are some indications that advanced age of 45 or older is a deterrent to migration among both those with leprosy and the clinically unapparent population. A positive association with migration and advanced age among birth migrants in the clinically unapparent population is likely reflective of historic population movement in the 1980s in Brazil, as this is no longer significant in recent past five-year and circular migration.

\section{Limitations}

We believe that our study highlights and is representative of national issues surrounding leprosy and migration in Brazil as (1) the population sample stemmed from endemic municipalities inside of clusters at high-risk for transmission and (2) the state of Maranhão is among the top states in Brazil with significant in- and outmigration. However, the study presented is a cross-sectional study limited to four municipalities in a hyperendemic area and thus subject to limitations. For example, outmigrants from the study sites were not included in this study and only data for migrants which are currently present in these sites compared to nonmigrant residents was included. Socioeconomic data only concerned the point in time when the research was conducted and thus excludes the timeframe when migration occurred. Data may not reflect the time of actual leprosy infection given a five-year average latency period. Data on stress factors pertained to the past five-years and could include stress during the postinfection time period.

Due to difficulties in establishing the sequence of events, interpretation of causal relationship should be taken with care. Events may be caused or compounded by migration and/or cause migration itself. Important indirect factors relevant to leprosy transmission need to be also considered in future research on migration and leprosy in highly endemic municipalities.

\section{Conclusions}

This is the first systematic cross-sectional study focusing on migration among people affected by leprosy. Psychosocial 
factors and healthcare access emerged as factors significantly associated with migration in this vulnerable population, in contrast to a clinically unapparent population. Findings point to the opportunity to assist migrants in maintaining ties to their home communities, thus not only potentially reducing stressors with separation from family and friends, but also potentially influencing the role of this separation as it may affect alcohol consumption. We included a discussion of both alcohol consumption and stressors as they pertain to reduced immune function and psychological well-being cited in the literature to support our findings; however, limited research still exists on the role of alcohol consumption and NTDs susceptibility. Further qualitative and quantitative longitudinal research addressing mild, moderate, and severe alcohol consumption could establish causal relationships and also explore the role of stress and substance use as risks for leprosy infection. Additionally, the role of acute stress through long-term migration and repetitive stress through circular migration could be explored.

As healthcare access emerged as a primary concern for migrants with leprosy, the health sector may consider restructuring services to meet the needs of migrating populations. Extended hours of operation, such as evening and weekend hours would be an important first step in this regard. Additionally, assistance with transportation to clinical facilities or providing mobile medical care could potentially alleviate problems associated with access. Facilitating the ease of healthcare access may increase early diagnosis and thus reduce advanced disability and improve medication adherence, while also supporting leprosy elimination and control in Brazil.

\section{Conflict of Interests}

The authors declare that they have no conflict of interests.

\section{Acknowledgments}

The authors thank the entire team of the Leprosy Control Program and the State Health Secretariat of Maranhão. Collaboration of the Municipalities' Health Secretariats and Primary Health Care Centers is acknowledged. They are also grateful to all patients that kindly agreed to participate in the study. Special thanks are due to Professor Marcel Tanner of the Swiss Tropical and Public Health Institute (SwissTPH) for his insightful comments on the manuscript and to Dr. Penelope Vounatsou (SwissTPH) for guidance on the statistical analysis. The research project "MAPATOPI" was financed by the Conselho Nacional de Desenvolvimento Científico e Tecnológico (CNPq) and the Department of Science and Technology of the Brazilian Ministry of Health (DECIT), Brazil. J. Heukelbach is research fellow from CNPq. C. H. Alencar was provided a scholarship through Fundação Coordenação de Aperfeiçoamento de Pessoal de Nível Superior (CAPES, Brazil). This publication is part of the MAPATOPI study (an interdisciplinary project providing evidence for improving the Brazilian leprosy control program), cofinanced by the Brazilian Research Council (CNPq) and the Department of Science and Technology of the Brazilian Ministry of Health (DECIT).

\section{References}

[1] WHO, "Closing the gap in a generation: health equity through action on the social determinants of health," Final Report, Commission on Social Determinants of Health (CSDH), World Health Organization, Geneva, Switzerland, 2008.

[2] J. Aagaard-Hansen, N. Nombela, and J. Alvar, "Population movement: a key factor in the epidemiology of neglected tropical diseases," Tropical Medicine and International Health, vol. 15, no. 11, pp. 1281-1288, 2010.

[3] S. Watts, “The Social Determinants of Schistosomiasis," 2008, http://www.tropika.net/review/051114-Schistosomiasis_Social_ Determinants/article.pdf.

[4] P. Allotey, D. D. Reidpath, and S. Pokhrel, "Social sciences research in neglected tropical diseases 1: the ongoing neglect in the neglected tropical diseases," Health Research Policy and Systems, vol. 8, article 32, 2010.

[5] J. Perlman, Globalization and the Urban Poor, World Institute for Development Economics Research, United Nations University, New York, NY, USA, 2007.

[6] D. Bhugra, "Migration and mental health," Acta Psychiatrica Scandinavica, vol. 109, no. 4, pp. 243-258, 2004.

[7] Y. Lu, "Rural-urban migration and health: evidence from longitudinal data in Indonesia," Social Science and Medicine, vol. 70, no. 3, pp. 412-419, 2010.

[8] G. Borges, J. Breslau, R. Orozco et al., "A cross-national study on Mexico-US migration, substance use and substance use disorders," Drug and Alcohol Dependence, vol. 117, no. 1, pp. 1623, 2011.

[9] V. García, "Problem drinking among transnational Mexican migrants: exploring migrant status and situational factors," Human Organization, vol. 67, no. 1, pp. 12-24, 2008.

[10] L. R. S. Kerr-Pontes, A. C. D. Montenegro, M. L. Barreto, G. L. Werneck, and H. Feldmeier, "Inequality and leprosy in Northeast Brazil: an ecological study," International Journal of Epidemiology, vol. 33, no. 2, pp. 262-269, 2004.

[11] A. M. Sales, A. Ponce de Leon, N. C. Düppre et al., "Leprosy among patient contacts: a multilevel study of risk factors," PLoS Neglected Tropical Diseases, vol. 5, no. 3, Article ID e1013, 2011.

[12] UNDP, Overcoming Barriers: Human Mobility and Development, UNDP, New York, NY, USA, 2009.

[13] G. Rayp and I. Ruyssen, "Africa on the move: an extended gravity model of intra-regional migration," APPAM, Maastricht, Netherlands, 2010.

[14] WHO, "Urbanization: an increasing risk factor for leishmaniasis," Weekly Epidemiological Records, vol. 77, pp. 365-372, 2002.

[15] L. Manderson, J. Aagaard-Hansen, P. Allotey, M. Gyapong, and J. Sommerfeld, "Social research on neglected diseases of poverty: continuing and emerging themes," PLoS Neglected Tropical Diseases, vol. 3, no. 2, article e332, 2009.

[16] C. Ackah and D. Medvedev, Internal Migration in Ghana: Determinants and Welfare Impacts, World Bank Ghana Poverty Assessment, 2010.

[17] P. Deshingkar, "Circular internal migration and development in India," in Migration and Development Within and Across 
Borders: Reserach and Policy Perspectives on Internal and International Migration, J. DeWind and J. Holdaway, Eds., pp. 161187, IOM and SSRC, Geneva, Switzerland, 2008.

[18] D. P. Lindstrom and N. Lauster, "Local economic opportunity and the competing risks of internal and U.S. migration in Zacatecas, Mexico," International Migration Review, vol. 35, no. 4, pp. 1232-1256, 2001.

[19] C. Murto, L. Ariza, A. R. Oliveira et al., "Motives and determinants for residence change after leprosy diagnosis, central Brazil," Leprosy Review, vol. 83, no. 1, pp. 16-23, 2012.

[20] A. B. Golgher, C. H. Rosa, and A. F. de Araújo Junior, "Determinants of migration in Brazil: regional polarization and poverty traps," Papeles de Poblacion, no. 56, pp. 135-171, 2008.

[21] M. L. F. Penna, M. L. De Wand-del-Rey Oliveira, and G. Penna, "Spatial distribution of leprosy in the amazon region of Brazil," Emerging Infectious Diseases, vol. 15, no. 4, pp. 650-652, 2009.

[22] V. Andrade, Evolução da Hanseniase no Brasil e Perspectivas Para Sua Eliminação como Um Problema de Saude Publica, Escola Nacional de Saúde Pública da Fundação Oswaldo Cruz, RJ, Brazil, 1996.

[23] R. Hudson, Brazil: A Country Study, GPO, Library of Congress, Washington, DC, USA, 1997.

[24] IBGE, Results of Population Census, 2010.

[25] $\mathrm{MoH}$, Brasil, "Indicadores de morbidade e factores de risco. Taxa de prevalencia de hanseniase," 2010, http://tabnet.datasus .gov.br/cgi/deftohtm.exe?idb2011/d09.def.

[26] IBGE. PNAD National Household Survey 2004/2009, "Publication approaches theoretical aspects of population mobility and analyzes the migration flows in Brazil," 2009, http:// www.ibge.gov.br/english/presidencia/noticias/noticia_visualiza .php?id_noticia=1928\&id_pagina=1.

[27] M. L. F. Penna, M. L. V. D. R. De Oliveira, and G. O. Penna, "The epidemiological behaviour of leprosy in Brazil," Leprosy Review, vol. 80, no. 3, pp. 332-344, 2009.

[28] J. Aagaard-Hansen and C. Chaignat, "Neglected tropical diseases: equity and social determinants," in WHO, E. Blas and A. S. Kurup, Eds., WHO, Geneva, Switzerland, 2010.

[29] M. Luhmann, W. Hofmann, M. Eid, and R. E. Lucas, "Subjective Well-Being and Adaptation to Life Events: A Meta-Analysis," 2011, http://psycnet.apa.org/?\&fa=main.doiLanding\&doi $=10.1037 / \mathrm{a} 0025948$.

[30] S. Cohen and G. M. Williamson, "Stress and infectious disease in humans," Psychological Bulletin, vol. 109, no. 1, pp. 5-24, 1991.

[31] R. Vivoli, S. Rovesti, P. Borella, and C. Cermelli, "Relation between psychoneuroendocrine profile in stressful conditions and antibodies to herpesvirus 6 and 7," Journal of Biological Regulators and Homeostatic Agents, vol. 22, no. 4, pp. 239-245, 2008.

[32] M. A. Dessen and C. V. Torres, "Family and socialization factors in Brazil: an overview," in Online Readings in Psychology and Culture, W. J. Lonner, D. L. Dinnel, S. A. Hayes, and D. N. Sattler, Eds., Center for Cross-Cultural Research, Western Washington University, Bellingham, Wash, USA, 2002.

[33] S. Kaloustian, Família Brasileira, a Base de Tudo, Cortez and UNICEF, Brasilia, 1994.

[34] K. M. Keyes, M. L. Hatzenbuehler, and D. S. Hasin, "Stressful life experiences, alcohol consumption, and alcohol use disorders: the epidemiologic evidence for four main types of stressors," Psychopharmacology, vol. 218, no. 1, pp. 1-17, 2011.

[35] K. Gupta, Y. Vaidehi, and N. Majumder, "Spatial mobility, alcohol Use, sexual behavior and sexual health among males in
India," AIDS and Behavior, vol. 14, no. 4, supplement, pp. S18S30, 2010.

[36] I. G. de Mattos, M. O. Ribeiro, I. C. de O. Netto, and P. A. d'Azevedo, "Tuberculosis: a study of 111 cases in an area of high prevalence in the extreme south of Brazil," Brazilian Journal of Infectious Diseases, vol. 10, no. 3, pp. 194-198, 2006.

[37] X. Li, C. J. Grossman, C. L. Mendenhall et al., "Host response to mycobacterial infection in the alcoholic rat: male and female dimorphism," Alcohol, vol. 16, no. 3, pp. 207-212, 1998.

[38] S. M. B. Ferreira, E. Ignotti, and M. A. Gamba, "Factors associated to relapse of leprosy in Mato Grosso, CentralWestern Brazil," Revista de Saude Publica, vol. 45, no. 4, pp. 756764, 2011.

[39] R. Weathermon and D. W. Crabb, "Alcohol and medication interactions," Alcohol Research and Health, vol. 23, no. 1, pp. 4054, 1999.

[40] O. A. Chichava, L. Ariza, A. R. Oliveira et al., "Reasons for interrupting multidrug therapy against leprosy: the patients' point of view," Leprosy Review, vol. 82, no. 1, pp. 78-79, 2011.

[41] A. Sheik-Mohamed and J. P. Velema, "Where health care has no access: the nomadic populations of sub-Saharan Africa," Tropical Medicine and International Health, vol. 4, no. 10, pp. 695-707, 1999.

[42] D. G. Storla, S. Yimer, and G. A. Bjune, "A systematic review of delay in the diagnosis and treatment of tuberculosis," BMC Public Health, vol. 8, article 15, 2008. 


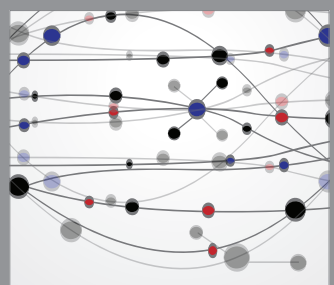

The Scientific World Journal
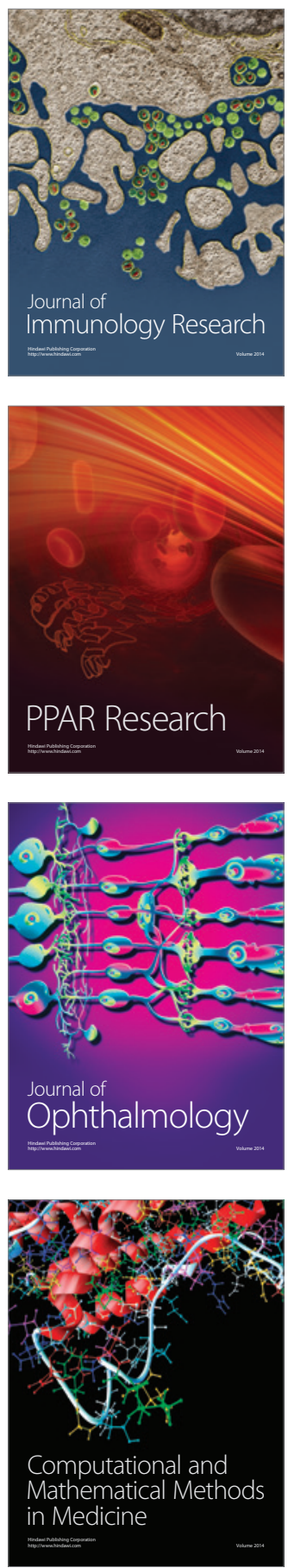

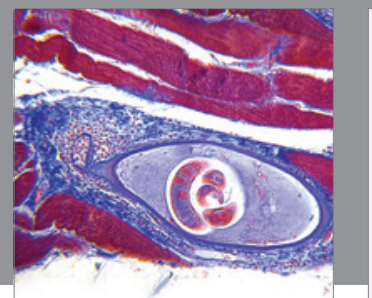

Gastroenterology

Research and Practice
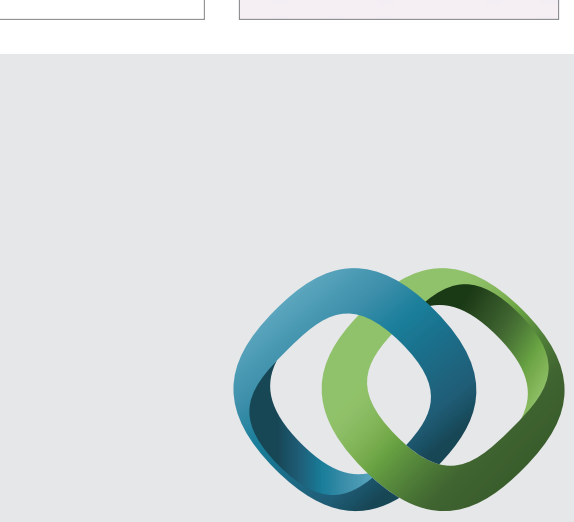

\section{Hindawi}

Submit your manuscripts at

http://www.hindawi.com
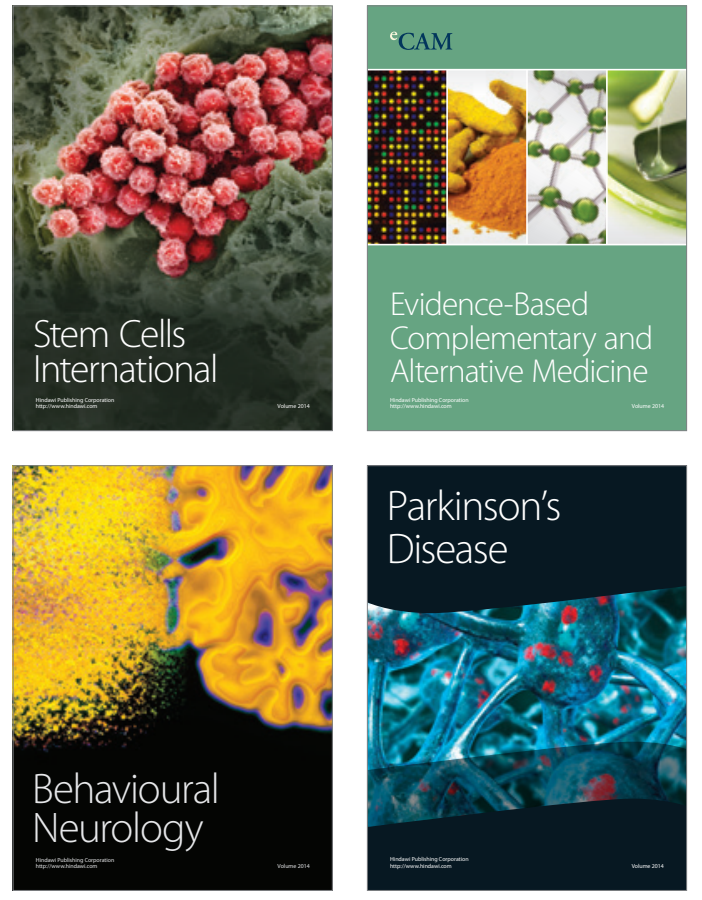
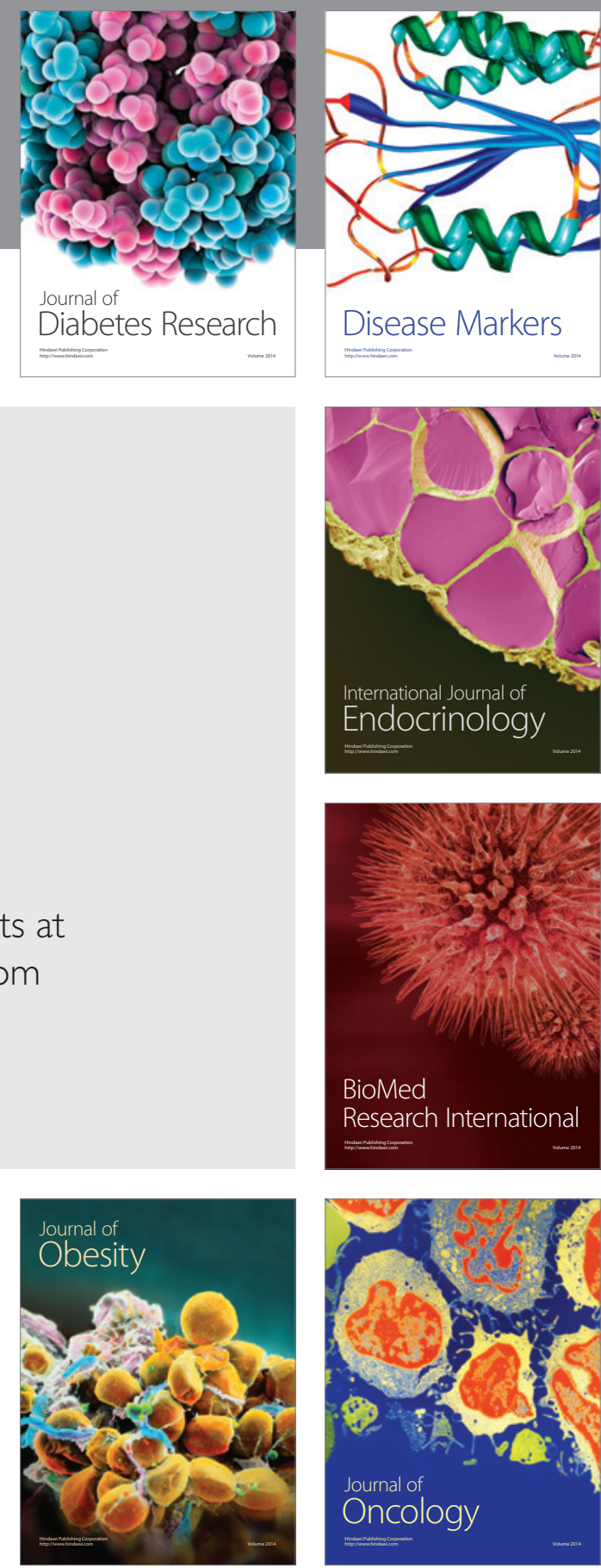

Disease Markers
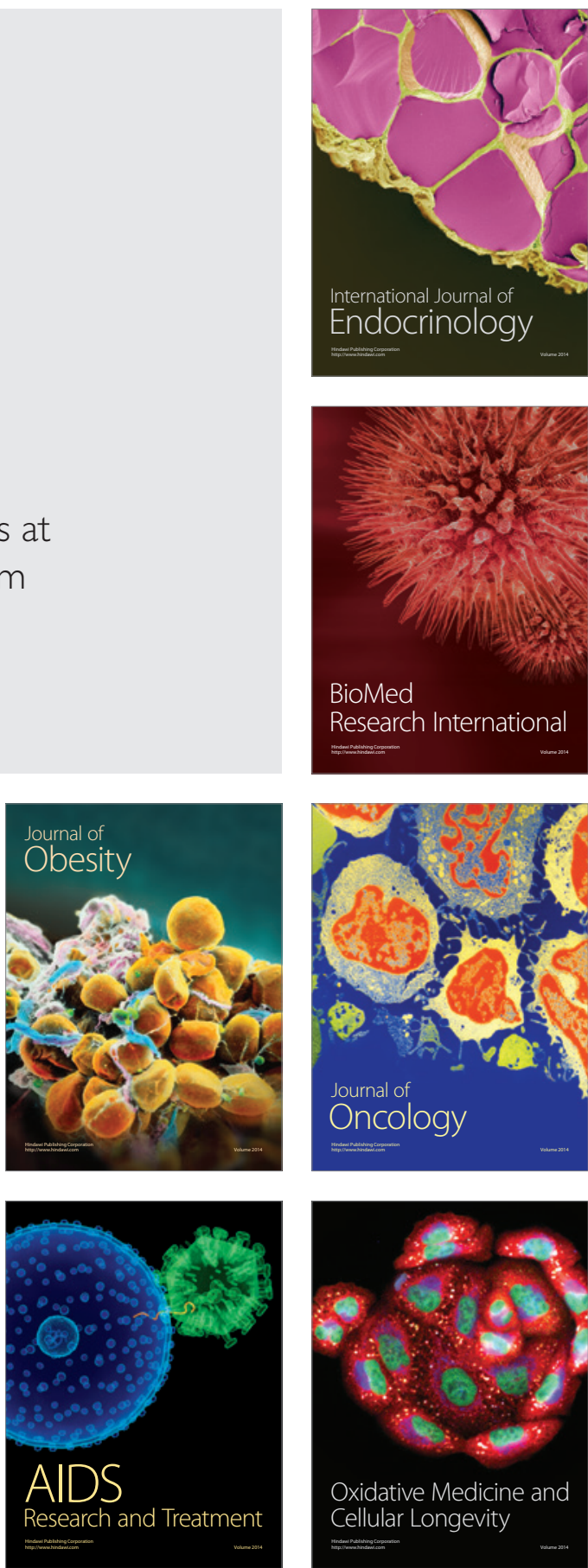